\title{
A Clinical Comparative Study of Propofol, Thiopentone Sodium and Midazolam as Anaesthetic Inducing Agents
}

\author{
Chandita Konwar ${ }^{1}$ \\ ${ }^{1}$ Department of Anaesthesiology \& Critical Care, Gauhati Medical College and Hospital. Guwahati, Assam, India.
}

\section{ABSTRACT}

\section{BACKGROUND}

The ideal intravenous anesthetic agent should be available in a stable, non-irritant solution, the solvent of which causes no adverse effects in normal usage, rapid acting i.e. unconsciousness should supervene in one arm-brain circulation time, short acting so that recovery is not prolonged and should be devoid of cardiovascular side effects especially myocardial depression, respiratory side effects particularly medullary depression, cerebral excitatory side effects, cerebral cortical side effects, should not liberate histamine or cause local tissue damage. Here in this study an attempt was made to evaluate clinically the practical utility of propofol and midazolam as alternatives to thiopentone for induction of anesthesia.

\section{METHODS}

Sixty adult patients of ASA I undergoing elective surgery were divided into three equal groups of twenty patients as follows- Group 1 (Thiopentone), Group 2 (Propofol) and Group 3 (Midazolam). Group 1 received $5 \mathrm{mg} / \mathrm{Kg}$ of thiopentone, group 2 received $2 \mathrm{mg} / \mathrm{Kg}$ of propofol. In group $1 \& 2$ given doses were found to be adequate for induction. In group 3, $0.1 \mathrm{mg} / \mathrm{Kg}$ of midazolam could induce 16 out of 20 patients. Remaining patients in group 3 required higher dose of midazolam. In this study, induction time, quality of induction, haemodynamic changes, recovery, and post-operative side effects were compared.

\section{RESULTS}

The result of this study showed that the induction time was shortest in case of thiopentone (31.65 secs +/-1.56 sec) and prolonged in Midazolam (150 secs +/-7.9 $\mathrm{sec}$ ) and intermediate in propofol group $(56.25+/-3.18 \mathrm{sec})$. Quality of induction is best with midazolam without any abnormal movements, coughing or bucking during laryngoscopy. Midazolam maintained the best cardiovascular stability. Propofol prevented any rise in B.P. after induction when compared to baseline induction. Recovery was best with propofol with orientation to time and space at 5 mins. Postoperative side effects were negligible in all the three groups.

\section{CONCLUSIONS}

Midazolam may be the drug of choice in cases where cardiovascular stability is of prime importance. Propofol maybe the drug of choice where early ambulation is absolutely necessary and also in cases of susceptible patients with reactive airways.
Corresponding Author: Dr. Chandita Konwar. House No. 12, Harabala Road, Near Bora Service, Ulubari, Guwahati-781007, Assam, India. E-mail: chandita3715@yahoo.co.in

DOI: $10.14260 /$ jemds/2020/583

How to Cite This Article:

Konwar C. A clinical comparative study of propofol, thiopentone sodium and midazolam as anesthetic inducing agents. J Evolution Med Dent Sci 2020;9(37):26802685, DOI: $10.14260 /$ jemds/2020/583

Submission 13-06-2020,

Peer Review 07-08-2020

Acceptance 13-08-2020,

Published 14-09-2020.

Copyright (C) 2020 JEMDS. This is an open access article distributed under Creative Commons Attribution License [Attribution 4.0 International (CC BY 4.0)]

\section{KEY WORDS}

Induction Agents, Thiopentone, Propofol, Midazolam 


\section{BACKGROUND}

General anaesthesia is a combination of analgesia, hypnosis and muscle relaxation. Hypnosis \& analgesia can be achieved with judicious combination of analgesic, nitrous oxide with other inhalation anaesthetics such as ether, halothane, enflurane, isoflurane, desflurane, sevoflurane which together produce analgesia, sleep and unconsciousness. Unfortunately, there is a rising cost of the newer inhalation anaesthetic agents and serious concern has been raised about its operating theatre pollution and hazards to personnel working in operating theatre as well as patients. With the availability of the intravenous anesthetic agents, it has gained importance and momentum. Ralph Waters from Madison, Wisconsin gave the first intravenous anesthesia with thiopentone but John Lundy was the first to publish a report on thiopentone anesthesia. Since then thiopentone is enjoying the status of the most widely used intravenous anaesthetic agent. However, use of thiopentone as an induction agent, was not followed by rapid recovery and repeated doses leads to cumulative effects producing a prolonged duration of action. In lighter plane of anaesthesia it causes laryngospasm and it has been reported to have caused bronchospasm in asthmatic patients.

From patient point of view, it has the advantage of producing rapid loss of consciousness without excitement, distress or the sensation of smothering often produced by a tightly pressed facemask. Intravenous anaesthetic agents are therefore gaining more popularity as an inducing agent. ${ }^{1}$ No agent fulfills all criteria of an ideal agent. In a quest to find an ideal intravenous induction agent, researches were carried out continuously. And newer agents like propofol and midazolam are compared with thiopentone.

Propofol introduced by James and Glen in 1980 has many advantages as compared to thiopentone which include a smooth induction, low incidence of side effects and rapid recovery. Propofol in its Cremophor formulation was first used clinically in 1977 by Kay \& Rolly. It was shown to possess many suitable characteristics for an intravenous anaesthetic agent. These included the rapid induction of anaesthesia, absence of excitatory effects followed by a rapid recovery. However, hypersensitivity reactions occurred with the Cremophor preparation therefore propofol has been prepared in an emulsion. The clinical use of this new formulation was first reported by Nightingale et al, who confirmed the general efficacy of propofol with rapid recovery without hangover effects.

Midazolam, a potent short-acting water- soluble benzodiazepine has been evaluated as an intravenous induction agent. Adequate doses of midazolam can reliably produce loss of consciousness. Except for a slower onset, midazolam compared favourably with thiopentone as the hypnotic drug in a balanced anaesthetic regimen. Midazolam synthesized in 1976 by Fryer and Walser, was first used in 1986 by Nilsson and colleagues. The minimal cardiovascular effects of midazolam, its almost total absence of excitatory effects apart from hiccough, the smooth transition to inhalation agent following subanaesthetic doses, absence of irritant effects, pain and venous sequelae following intravenous injection and its acceptability to patients make it an alternative to thiopentone in situation where the latter is contraindicated.
Here, in this study an attempt was made to evaluate clinically the practical utility of propofol and midazolam as alternatives to thiopentone for induction of anesthesia. The primary aim was to study and compare the time taken for induction, the efficacy and side effects of propofol, thiopentone and midazolam. The secondary aim was to study and compare the quality of recovery of propofol, thiopentone and midazolam.

\section{METHODS}

This study was carried out under the Dept. of Anesthesiology and Critical Care, Gauhati Medical College with prior approval from the institutional ethical committee. Informed written consent were obtained from the participants. The study was carried out from December 2018 to October 2019. Marudhachalam K.S. noted the induction time as $36.45+/$ 1.79 secs in the thiopentone group. To detect a difference of 10 secs with a power of .9 and significance of $5 \%$ one patient in each group is required. Karl E Becker in 1978 observed time of induction in patients for thiopentone $26+/ 22.3 \mathrm{~S} \mathrm{D}$, so to detect a difference of 5 secs with a power of .9 and alpha value of .05 , five patients in each group were required. So, we decided to take 20 patients in each group. Sixty adult patients were randomly selected and enrolled in the study. Both male and female of ASA grade $1 \& 2$, of age group 18 - 60 years undergoing various elective surgical operations in different surgical and gynecological units under the department of Anesthesiology and Critical Care, Gauhati Medical College were included in the present study. Patients were divided in three groups 20 patients each. Under Group 1: Thiopentone sodium, Group 2: Propofol, Group 3: Midazolam.

Selection of cases.

\section{Exclusion Criteria}

1. Neurological disease.

2. Disease involving urinary system.

3. Disease of the skeletal system.

4. Gross cardiovascular disorder.

5. Gross respiratory disorder.

6. Metabolic disorder.

7. Patients admitted for emergency surgery.

The patients were visited in the wards and preanesthetic assessment was performed on all the cases. The detailed history of each patient along with the findings of clinical examination and investigations were recorded. Tablet Alprazolam [0.25 mg] was administered per oral the night before surgery.

In all the cases a standard anesthesia protocol was employed. Shifting the patients into the operation theatre, monitor was attached and baseline ECG [3 lead configuration, monitored lead was lead II], heart rate [HR], automated noninvasive [oscillometric method] systolic, diastolic and mean blood pressure [SBP, DBP and MAP respectively and peripheral arterial oxygen saturation $\left[\mathrm{SpO}_{2}\right]$ were recorded. $\mathrm{A}$ lactated ringer's solution was started at the rate of $5 \mathrm{ml} /$ $\mathrm{Kg} / \mathrm{min}$ via an 18 gauge intravenous [IV] cannula in a suitable vein in the forearm preferably left side in a righthanded 
person. Then patients were premedicated with fentanyl [1 $\mathrm{mcg} / \mathrm{Kg}$ ] IV fifteen minutes prior to induction of anesthesia. Glycopyrrolate $[0.2 \mathrm{mg} / \mathrm{Kg}$ ] intramuscularly thirty minutes prior to induction of anesthesia. Preoxygenation [for three minutes] was carried out with $100 \%$ oxygen.

Induction was carried out with sleep dose of $2.5 \%$ solution of thiopentone sodium ( $5 \mathrm{mg} / \mathrm{Kg}$ of body weight) in group 1; $1 \%$ emulsion of Propofol ( $2 \mathrm{mg} / \mathrm{Kg}$ body weight) in group 2 and Midazolam Hydrochloride $(0.15 \mathrm{mg} / \mathrm{Kg}$ of body weight) in group 3. The time taken for induction was defined as the time from end of injection of the drug till loss of eyelash reflex. Assisted ventilation was carried out with oxygen and nitrous oxide (50:50) as dictated by clinical circumstances. During this period excitatory signs like hypertonus, spontaneous movement, twitching, tremor and apnoea were noted. Apnoea taken as any period of absence of spontaneous respiration for more than 30 seconds. In all patients, muscle relaxation was achieved with vecuronium bromide $0.1 \mathrm{mg} / \mathrm{Kg}$ given intravenously after loss of eyelash reflex. After complete paralysis, direct laryngoscopy done and patients were intubated. Respiratory side effects like cough, hiccup, laryngospasm was noted. The HR, SBP, DBP, MAP and SpO2 was measured at baseline, after induction of anesthesia and immediately after tracheal intubation.

\section{Statistical Analysis}

Nominal data and categorical data are presented as absolute number and percentage. Continuous data was evaluated for normal distribution. For normal distributed data central tendency is represented by mean and dispersion is represented by standard deviation. Hypothesis testing was carried out by-Social Science Statistics available at socscistatistic.com A p-value of .05 is considered as significant.

\section{RESULTS}

Patients selected were of different ages ranging from 18 years to 60 years of either sex and body weight ranging from $35 \mathrm{~kg}$ to $60 \mathrm{~kg}$. Demographic parameters are presented in Table 1.

One-way ANOVA test for independent sample for 3 groups reveal the f ratio of 146.84 which corresponds to a $\mathrm{p}$ value < 0.0001 . The main induction time and dispersion are mentioned in table 2. Data on induction time is presented in Table 2. Mean induction time (Mean $+/$-SD) with propofol was $56.25+/-3.18$ whereas with thiopentone it was $31.65+/-1.56$ and with midazolam it was $150+/-7.94(\mathrm{p}<0.01)$. (Table 2)

Data on various side effects are presented in table 3 and 4 . There were no significant differences in the respiratory side effects between the groups, though patients having apnoea during induction was higher in the propofol group.

Table 5 shows the value of systolic \& diastolic pressures and pulse rate at various time intervals along with their statistical significance. There was mean fall of blood pressure in both thiopentone and propofol group, but these changes were statistically significant and more pronounced in the propofol group than in the thiopentone group. No significant change in both systolic and diastolic pressure 2 minutes after induction in the midazolam group was observed.

However, after intubation, following induction with midazolam and thiopentone a mean increase of both systolic \& diastolic blood pressure was observed from its pre-induction level, which is considered to be a significant change. But in the propofol group, although there was significant fall for both systolic and diastolic pressure following induction with propofol; after intubation there was rise of both systolic and diastolic blood pressure nearly to its pre-induction level due to pressure response so, no significant change of both systolic and diastolic pressure after intubation in propofol group was recorded in this study. The pulse rate after intubation in thiopentone group was significantly higher than in the propofol and midazolam group.

\begin{tabular}{|c|c|c|c|}
\hline Group & Group 1 & Group 2 & Group 3 \\
\hline No. of patients & 20 & 20 & 20 \\
\hline Mean age with SD (years) & $36.35 \pm 1.96$ & $33.85 \pm 2.22$ & $31.4 \pm 2.17$ \\
\hline Mean Weight with SD (Kg) & $50.5 \pm 1.23$ & $46.7 \pm 1.42$ & $51.1 \pm 1.27$ \\
\hline No. of male & 4 & 3 & 6 \\
\hline No. of female & 16 & 17 & 14 \\
\hline \multicolumn{4}{|c|}{ Table 1. Demographic Data of Patients in the Three Study Groups } \\
\hline Group & Mean +/_SD & \multicolumn{2}{|c|}{ P Value } \\
\hline Group 1 & $31.65 \pm 1.56$ & & \\
\hline Group 2 & $56.25 \pm 3.18$ & \multicolumn{2}{|c|}{$\mathrm{p}<0.01$} \\
\hline Group 3 & $150.0 \pm 7.94$ & & \\
\hline \multicolumn{4}{|c|}{ Table 2. Induction Time [in Seconds] in the Three Groups } \\
\hline
\end{tabular}

\begin{tabular}{|lcc|cc|}
\hline Group & Hypertonus & Spontaneous Movement & Twitching & Tremor \\
Group 1 & 0 & $1(5 \%)$ & 0 & 0 \\
Group 2 & 0 & $1(5 \%)$ & 0 & 0 \\
Group 3 & 0 & 0 & 0 & 0 \\
\hline \multicolumn{4}{|c|}{ Table 3. Incidence of Excitatory Signs in the } & Three Groups \\
\hline
\end{tabular}

\begin{tabular}{|cccc|}
\hline Group & Coughs/Bucking & Hiccups & Laryngospasm / Bronchospasm \\
Group 1 & $3(15 \%)$ & 0 & 0 \\
Group 2 & $1(5 \%)$ & 0 & 0 \\
Group 3 & 0 & 0 & $1(5 \%)$ \\
\hline \multicolumn{2}{|c|}{ Table 4. Incidences of Respiratory Side Effects in the Three Groups } \\
\hline
\end{tabular}

\begin{tabular}{|c|c|c|c|c|c|c|}
\hline Group & $\begin{array}{l}\text { Systolic } \\
\text { A }\end{array}$ & B.P. & C & $\begin{array}{c}\text { Diastolic } \\
\text { A }\end{array}$ & B.P. & C \\
\hline Group 1 & $117.9 \pm 2.19$ & $\begin{array}{c}112.5 \pm 2.33 \\
(\mathrm{p}<0.01)\end{array}$ & $\begin{array}{c}131 \pm 2.54 \\
(\mathrm{p}<0.01)\end{array}$ & $76.8 \pm 1.42$ & $\begin{array}{c}75.8 \pm 1.32 \\
(p>0.01)\end{array}$ & $\begin{array}{l}85 \pm 1.32 \\
(p<0.01)\end{array}$ \\
\hline Group 2 & $126 \pm 3.12$ & $\begin{array}{c}104.5 \pm 2.50 \\
(p<0.01)\end{array}$ & $\begin{array}{c}126 \pm 2.78 \\
(p>0.01)\end{array}$ & $81 \pm 1.21$ & $\begin{array}{c}74.5 \pm 1.32 \\
(p<0.01)\end{array}$ & $\begin{array}{l}82 \pm 1.52 \\
(p>0.01)\end{array}$ \\
\hline Group 3 & $124.5 \pm 2.40$ & $\begin{array}{c}124 \pm 2.28 \\
(p>0.01)\end{array}$ & $\begin{array}{c}136.5 \pm 2.21 \\
(\mathrm{p}<0.01)\end{array}$ & $79 \pm 1.29$ & $\begin{array}{l}80 \pm 1.05 \\
(p>0.01)\end{array}$ & $\begin{array}{c}86.8 \pm 1.46 \\
(\mathrm{p}<0.01)\end{array}$ \\
\hline \multicolumn{7}{|c|}{$\begin{array}{c}\text { Table 5. Haemodynamic Values at Different Time Points } \\
\text { in the Three Study Groups }\end{array}$} \\
\hline
\end{tabular}

\begin{tabular}{|ccc|cc|}
\hline Time & 5 Mins. & 15 Mins. & 30 Mins. & 60 Mins. \\
$\begin{array}{c}\text { Score } \\
\text { Wakefulness }\end{array}$ & 012 & 012 & 012 & 012 \\
Group l & 1541 & 776 & 0416 & 0020 \\
Group 2 & 965 & 7310 & 0218 & 0020 \\
Group 3 & 1730 & 974 & 1514 & 0020 \\
Movement & 758 & 4313 & 0020 & 0020 \\
Group l & 4610 & 1415 & 0020 & 0020 \\
Group 2 & 947 & 7211 & 0020 & 0020 \\
Group 3 & Table 6. Recovery Table \\
\hline \multicolumn{5}{c}{} \\
\hline
\end{tabular}

\section{Wakefulness}

Score 0 - Eye opening on verbal command but drowsy.

Score 1 - Eye opening on verbal command with clearheadedness.

Score 2 - Fully awake with orientation to time and place.

\section{Movement}

Score 0 - No limb movement

Score 1 - Two limb movement 
Score 2 - Four limb movement with head raising.

Recovery is noted after patient is extubated at 5 minutes, 15 minutes, 30 minutes and 60 minutes.

\section{DISCUSSION}

Use of intravenous anesthetic agents became possible with drugs available since 1930 and it rapidly became popular. Since the days of the first publication of a report by John Lundy, thiopentone was enjoying the status of the most widely used intravenous anesthetic agent. The other newer agents like propofol and midazolam are being compared with thiopentone. It is a rapidly acting drug where one arm brain circulation time is taken into consideration and this can vary between 10 to 30 seconds depending on the physical condition of the patient as observed by Dundee J. W. et al, $1982 .{ }^{2}$ Marudhachalam K. S. et al $1996^{3}$, noted the induction time for thiopentone to be $36.45+/-1.79$ seconds. The result of this present study showed that the induction time was shortest in case of thiopentone being $31.65 \mathrm{sec} \pm 1.56 \mathrm{sec}$ and prolonged in midazolam being $150 \mathrm{sec} \pm 7.9 \mathrm{sec}$ and intermediate in propofol group being $56.25 \pm 3.18$ secs. The induction time was measured as the interval from the start of injection to the onset of unconsciousness as indicated by the loss of eyelash reflex. Nightingale et al. in $1985^{4}$ recorded the induction time for propofol as 30 seconds. It was seen that the induction time recorded with midazolam in this study is comparable to that recorded by Freuchen et al [1983]. ${ }^{5}$

Quality of induction is best with midazolam without any abnormal muscle movement and coughing and bucking during laryngoscopy and intubation. N.W. Lees et al $1985^{6}$ reported 5 $\%$ incidence of muscle movement in both thiopentone and propofol groups and seen only in unpremeditated patients. McCollum and Dundee $1986^{7}$ graded the acceptability of two groups and its comparison amongst 300 unpremeditated patients. Induction of anaesthesia with thiopentone was assessed as $96 \%$ acceptable and in case of propofol it was $87 \%$ which was associated with marked unwanted excitatory effects like abnormal movements or respiratory effects like cough, hiccough, laryngospasm. G. Wilmot et al $1993^{8}$ noted no inter groups differences between thiopentone \& propofol in the assessment of ease of induction and no patient developed laryngospasm. In the thiopentone group 13 of 30 patients and 11 out of 29 patients in the propofol group coughed during passage of endotracheal tube while no patient bucked after intubation. Intubation was classed as very easy in 22 patients [73.3\%] in the thiopentone group compared with 23 patients [79 \%] in the propofol group. The remaining 8 in the thiopentone group was classed as not difficult, of the remaining 6 in the propofol group, 4 were classified as not difficult and 2 as moderately difficult. There was no failed intubation.

In this present study in the thiopentone group intubation was excellent in 17 patients [85\%] compared to 19 patients [95 \%] in the propofol group. It was noted that in the thiopentone group three patients compared with one patient in the propofol group bucked during passage of endotracheal tube. P.C. Khandelwal et al. $1995^{9}$ in 60 healthy patients divided into equal groups namely thiopentone and propofol, noted the excitatory signs like cough, hiccough, laryngospasm following the induction of anaesthesia. The propofol group had greater spontaneous movement 16 [53.33\%] than the thiopentone group 10 [33.33\%] at the time of induction, but the difference was not significant. The number of patients having apnoea during induction was higher in the propofol group. In both the groups 4 patient [13.33\%] each had developed cough and one patient [3.33\%] in the thiopentone group developed hiccough. K. S. Marudhachalam et al $1996^{3}$ reported similar findings. They concluded that propofol produces smooth and rapid induction of anaesthesia, but apnoea, abnormal spontaneous movements are important side-effect. They stated that the spontaneous movements did not last for more than 25 seconds and did not interfere in induction. In this present study one case in the thiopentone group had spontaneous movement of the arm and one case had apnoea, whereas in the propofol group one patient had spontaneous movement following induction which was mild and subsided after 15 seconds and two cases of apnoea was noted. The percentage of spontaneous movement in case of propofol was found to be much less in our study than that of others may be due to the small number of cases studied in our series.

In our study Midazolam maintained the best cardiovascular stability without any change in blood pressure and pulse rate. Propofol prevented rise of B. P. after intubation when compared to baseline induction. P. Nightingale et al[1985] ${ }^{4}$ in their study found that decrease in arterial blood pressure which occurred after both induction agents were greater after propofol than after thiopentone $[p<0.05]$. There was no significant difference in the increase in the heart rate which occurred after the injection of either propofol or thiopentone. Lippmann et al (1988) ${ }^{10}$ noted a greater reduction in mean arterial pressure on induction in patients anaesthetized with propofol than thiopentone. Heart rate was increased by thiopentone but unchanged after propofol. Gold et al (1987) ${ }^{11}$ reported a $14 \%$ decrease in systolic arterial pressure following propofol when given over 20 seconds. Keaveny (1988) ${ }^{12}$ commented upon minimal decrease in mean arterial pressure two minutes after intubation when using propofol, whereas Coley et al (1989) ${ }^{13}$ reported a decrease of $23 \%$ of B.P. after $2.25 \mathrm{mg} / \mathrm{Kg}$ of propofol. In a comparative study of propofol by S L Zettervall et al. [2015] ${ }^{14}$ for rapid sequence induction in trauma, they concluded that the propofol group had no significant changes in any postinduction parameter compared to pre-induction parameter.

G. Wilmont.N. Bhimsan $1993^{8}$ studied the hemodynamic change 30 seconds after fixed induction dose of thiopentone or propofol in patients scheduled for elective surgery. The immediate post - induction average systolic pressure in the thiopentone group is decreased while the post - intubation systolic pressure after induction but the subsequent pressor response to intubation was markedly attenuated compared with baseline. Compared with baseline there was increase $(\mathrm{p}<$ 0.01 ) in heart rate in both group from induction of anesthesia to the end of study

P. C. Khandelwal et al (1995) ${ }^{9}$ noted that the systolic and diastolic arterial pressures showed a considerable decrease with propofol. The decrease was less with thiopentone. These patients were all normovolaemic and relatively fit. There was decrease in the heart rate by less than $1 \%$ in propofol group. After intubation there was a significant rise in systolic and diastolic arterial pressures and heart rate in both groups but 
the rise was lower, though not significantly so in the propofol group.

While considering the hemodynamic effects in the present study in the thiopentone group (Group 1; 2 minutes after induction, there was a mean fall of systolic blood pressure by $5.4 \mathrm{~mm}$ of $\mathrm{Hg}$ from its pre-induction systolic pressure which is statistically significant. But there was no significant change in the diastolic pressure. While the mean fall of systolic and diastolic pressure in propofol group (Group II) 2 minutes after induction were $21.5 \mathrm{~mm}$ of $\mathrm{Hg}$ and $6.5 \mathrm{~mm}$ of $\mathrm{Hg}$ respectively. These changes were statistically significant and more pronounced than in the thiopentone group. No significant change in both systolic and diastolic pressure 2 minutes after induction in the midazolam group (Group lli) was observed. However, after intubation following induction with midazolam a mean increase of both systolic and diastolic blood pressure of $12 \mathrm{~mm}$ of $\mathrm{Hg}$ and $7.8 \mathrm{~mm}$ of $\mathrm{Hg}$, was observed from its preinduction level, which is considered to be a significant change. In the thiopentone group also there is mean increase of 12.6 $\mathrm{mm}$ of $\mathrm{Hg}$ and $8.2 \mathrm{~mm}$ of $\mathrm{Hg}$ of systolic and diastolic blood pressure following intubation. Although there was significant fall for systolic and diastolic pressure following induction with propofol, after intubation there was rise of both systolic and diastolic blood pressure nearly to its pre-induction level due to pressure response so no significant change of both systolic and diastolic pressure after intubation in propofol group was recorded in this study.

There was mean increase of pulse rate of $10 / \mathrm{min}$ and 20/min following 2 minutes after induction and intubation respectively in the thiopentone group [Group 1] while in propofol group [Group II] the increase in the pulse rate was $7 / \mathrm{min}$ and $11 / \mathrm{min}$ respectively. An increase in $7 / \mathrm{min}$ and $13 / \mathrm{min}$ in the pulse rate after induction and intubation in midazolam group was observed, which was statistically significant. All the above haemodynamic changes observed in this present study corroborates with other workers observation.

R.D.M. Jones et al 199415 studied the haemodynamic changes following induction of anesthesia between thiopentone- $4 \mathrm{mg} / \mathrm{Kg}$, propofol $2.5 \mathrm{mg} / \mathrm{Kg}$, and midazolam $0.5 \mathrm{mg} / \mathrm{Kg}$. The maximum decline in mean arterial pressure recorded showed a significant difference between the three induction agents at both one minutes and five minutes. Propofol caused the greatest and most protracted fall in blood pressure which was maximal five minutes after induction. Propofol and thiopentone administration were associated with an average rise in heart rate of $10 \%$ above baseline values while increase in pulse rate in midazolam group was 5 $\%$.

No changes in the oxygen saturation was observed after induction and intubation in all the three groups of the present study. Recovery was best with propofol with complete recovery with orientation of time and space at 5 minutes in a number of cases. Thiopentone showed intermediate and midazolam longest recovery time.

Mackenzie and Grant [1985] ${ }^{16}$ reported rapid immediate recovery from anesthesia induced with propofol. Patients opened their eyes on command approximately five minutes after the end of anesthesia and were able to recall their date of birth approximately one minutes later. Recovery time were longer after anesthesia induced with thiopentone. Gold et al [1987] ${ }^{11}$ stated similar findings. Saifudin Rashiq et al. 199417 have also noted that induction with propofol leads to recovery that is faster than that seen after thiopentone. K.S. Marudhachalam et al $1996^{3}$ has also noted smooth and swift recovery after propofol.

When recovery was compared between the three group under the present study at 5 minutes it was observed that 5 patients in propofol group and one patient in the thiopentone and none in the midazolam group were fully awake with score 2 with orientation to time and space. However, 4 patients in thiopentone group, 3 patients in midazolam group and 6 patients in propofol group scored 1 point each opening their eyes to verbal command with a clear head. So, we can conclude that recovery in the propofol group was quicker and more complete than the other two groups. Post-operative side effects were negligible in all three group

These results observed in the present studied tallied with studies carried out by other workers. During the early recovery the most striking features was lower incidence of all side effects with propofol. Nausea and vomiting occurred more frequently after thiopentone. Milligan et al 198718 in a retrospective analysis of 200 patients with propofol only 3 cases of nausea were recorded in the first hour after operation. McCollum et al $1988^{19}$ also noted that post- operative nausea and vomiting was lesser with propofol than thiopentone. In case of midazolam A.M. Holloway et al $1982^{20}$ noted no case of nausea and vomiting in their study. W. H. J. Cole $1982^{21}$ noted the incidence of post- operative vomiting as $1 \%$ following midazolam.

In the present study two patients had headache and one patient had vomiting in the immediate post-operative period in the thiopentone group. While one patient developed nausea in the post-operative period in the propofol group which subsided without any treatment. Although the recovery in the midazolam group was slower, in all cases it was uneventful without the above few side effects of thiopentone and propofol group.

A distinguishing feature of propofol is pain experienced on injection into veins on the dorsum of the hand. Scott R.P. E. et $\mathrm{al}^{22}$ 1988; Morton N. S. $1990^{23}$ alleviated pain by injecting $1 \%$ lignocaine $1 \mathrm{ml}$ intravenously before giving propofol. P. C. Khandelwal et al $1995^{9}$ compared thiopentone with $1 \%$ emulsion of propofol injected over 20 seconds. Number of patients who were comfortable when injected into a vein was more in the thiopentone group as compared to the propofol group and this difference was statistically significant [p < 0.01]. K. S. Marudhachalam et al $1996^{3}$ observed incidence of pain as $55 \%$ and $20 \%$ with propofol and thiopentone respectively.

In this present study pain was not observed following propofol injection mixed with [2 $\mathrm{mL}$ ] of $1 \%$ lignocaine in all the cases as stated by Morton N. S. $1990 .{ }^{23}$ In a comparative evaluation by P Hari Keerthy et al [2014] ${ }^{24}$ of propofol and midazolam in terms of onset of action, heart rate, systolic and diastolic blood pressure, respiratory rate, recovery period, side effects, pain during injection of agent- concluded that there were no significant differences between the two groups. But, pain during injection was a significant adverse effect in the propofol group, unlike that observed in our study as we used propofol mixed with $1 \%$ lignocaine. Cardiovascular parameters remained stable throughout the procedure in both the groups and required no intervention. Recovery was faster 
in the propofol group compared to the midazolam group which tallies with our study.

\section{CONCLUSIONS}

No marked advantages were observed with the newer intravenous inducing agents over the conventional agent thiopentone which may eliminate thiopentone totally from the practice in favor of propofol and midazolam. But midazolam may be the drug of choice in those cases where cardiovascular stability is of prime importance. Propofol may be the drug of choice where early ambulation of the patient is absolutely necessary and also in cases of susceptible patients with reactive airways.

Financial or Other Competing Interests: None.

\section{REFERENCES}

[1] Dundee JW. Intravenous anesthesia In: Evans FT, Grey C, eds General anesthesia. London: Butterworths 1965: p. 48.

[2] Dundee JW, Hassard TH, McGowan WAW, et al. The induction dose of thiopentone. Anesthesia 1982;37(12):1176-84.

[3] Marudhachalam KS, Sharma K, Chari P. Comparison of propofol and thiopentone for induction and recovery of anesthesia in children. J Anaesth Clin Pharma 1996;12:185-8

[4] Nightingale P, Petts NV, Healy TE, et al. Induction of anesthesia with propofol (Diprivan) or thiopentone an interaction with suxamethonium, atracurium and vecuronium. Post Graduate Med J 1985;61(Suppl 3):31-4.

[5] Freuchen IB, Ostergaard J, Mikkelsen BO. Midazolam compared with thiopentone as an inducing agent. Curr Therapeu Res 1983;34(2):269-73.

[6] Lees NW, McCulloch M, Mair WB. Propofol [Diprivan] for induction and maintenance of anesthesia. Postgrad Med J 1985;61(Suppl 3):88-9.

[7] McCollum JS, Dundee JW. Comparison of induction characteristics of four intravenous anesthetic agents. Anesthesia 1986;41(10):995-1000.

[8] Wilmot G, Bhimsan N. Intubating conditions and haemodynamic changes following thiopentone or propofol for early tracheal intubation. Can J Anaesth 1993;40(3):201-5.
[9] Khandelwal PC, Gairola RL, Lal A. Comparison of induction characteristics of propofol with thiopentone. Indian J Anaesth 1995;43:243.

[10] Lippmann M, Paicius R, Gingerich S, et al. A controlled study of the haemodynamic effects of propofol versus thiopentone during anaesthesia induction. Seminars in Anaesth 1988;7(Suppl 1):116-22.

[11] Gold MI, Abraham EC, Herrington C. A controlled investigation of propofol, thiopentone and methohexitone. Can J Anaesth 1987;34(5);478-83.

[12] Keaveny JP, Knell PJ. Intubation under induction doses of propofol. Anaesthesia 1988;43 Suppl:80-1.

[13] Coley S, Mobley KA, Bone ME, et al. Haemodynamic changes after induction of anaesthesia and tracheal intubation following propofol or thiopentone in patients of ASA grade I and III. Br J Anaesth 1989;63(4):423-8.

[14] Zettervall SL, Sirajuddin S, Akst S, et al. Use of Propofol as an induction agent in the acutely injured patient. Eur J Trauma Emerg Surg 2015;41(4):405-11.

[15] Jones RD, Visram AR. Chan MM, et al. A comparison of three induction agents in paediatric anaesthesia-cardiovascular effects and recovery. Anaesth Intensive Care 1994:22(5):545-55.

[16] Mackenzie N, Grant IS. Comparison of new emulsion formulation of propofol with methohexitone and thiopentone for induction of anaesthesia in day cases. $\mathrm{Br}$ J Aneasth 1985;57(8):725-31.

[17] Rashiq S, Gallant B, Grace M. et al. Recovery characteristics following induction of anaesthesia with a combination of thiopentone and propofol. Can J Anaesth 1994;41(12):1166-71.

[18] Milligan KR, McCollum JS, Dundee JW. An investigation into the antiemetic effect of propofol. Br J Clin Pharmacology 1087;23:608-9.

[19] McCollum JS, Milligan KR, Dundee JW. The antiemetic action of propofol. Anaesthesia 1988;43(3):239-40.

[20] Holloway AM, Brock-Utne JG, Sommerville TE, et al. Midazolam, a new intravenous induction agent for anaesthesia. S Afr Med J 1982:61(8):274-6.

[21] Cole WH. Midazolam in paediatric anaesthesia. Anaesth Intensive Care 1982;10(1):36-9.

[22] Scott RP, Saunders DA, Norman J. Propofol clinical strategies for preventing the pain of injection. Anaesthesia 1988;43(6):492-4.

[23] Morton NS. Abolition of injection pain due to propofol in children. Anaesthesia 1990;45(1):70.

[24] Keerthy PH, Balakrishna R, Srungeri KM, et al. Comparative evaluation of propofol and midazolam as conscious sedatives in minor oral surgery. J Maxillofac Oral Surg 2015;14(3):773-83. 